\title{
antibacterial activity
}

3 Fabienne Quilès ${ }^{1}$, Danielle Barth, ${ }^{2}$ Oliver Peric ${ }^{3}$, Georg E. Fantner ${ }^{3}$, Grégory Francius ${ }^{1}$ *

4

$5 \quad{ }^{1}$ Université de Lorraine, CNRS, LCPME, F-54000 Nancy, France.

$6 \quad{ }^{2}$ Université de Lorraine, CNRS, LRGP, F-54000 Nancy, France.

$7 \quad{ }^{3}$ Ecole Polytechnique Fédérale de Lausanne, Institute for Bioengineering, Laboratory for Bio

8 \& Nanoinstrumentation, Bâtiment BM 3109 Station 17, Lausanne, CH-1015, Switzerland.

9

10

11

* Corresponding author:

12

Email: gregory.francius@univ-lorraine.fr

13

Laboratoire de Chimie Physique et Microbiologie pour les Matériaux et l'Environnement,

LCPME, UMR 7564, 405, rue de Vandoeuvre, 54600 Villers-lès-Nancy, France

15

Phone: +33 372747416 


\section{Abstract}

Bacterial resistance to conventional antibiotics is of major concern. Antimicrobial peptides (AMPs) are considered as excellent alternatives. Among them, D-cateslytin (D-Ctl, derivative of a host defense peptide), has shown high efficiency against a broad spectrum of bacteria. The first target of AMPs is the outer membrane of the bacterium. However, the role of bacterial cell-wall structures on D-Ctl mechanism of action has not yet been understood. In this study, we investigated the activity of D-Ctl on two isogenic strains of E. coli: one is nude of any parietal structures, the other constitutively overexpresses only Type 1 fimbriae. We studied the damages caused by D-Ctl at several initial concentrations of bacteria and D-Ctl, and times of exposure to D-Ctl were examined using a combination of epifluorescence microscopy, atomic force microscopy (AFM), and Fourier transform infrared spectroscopy in attenuated total reflectance mode (ATR-FTIR). The analysis of nanomechanical and spectrochemical properties related to the antibacterial mechanism showed a concentration dependent activity. Whereas the membrane permeabilization was evidenced for all concentrations of D-Ctl and both mutants, no pore formation was observed. The bacterial stiffness is modified dramatically concomitantly to major membrane damages and changes in the spectral fingerprints of the bacteria. In case of the occurrence of Type 1 fimbriae only, an intracellular activity was additionally detected. Our results evidenced that D-Ctl activity is highly impacted by the cell-wall external structures and surface properties of the bacteria.

Keywords: parietal structures, antimicrobial peptide, D-cateslytin, mechanism of action, AFM, epifluorescence microscopy, infrared spectroscopy, Escherichia coli 


\section{Introduction}

Bacterial resistance to conventional antibiotics has been increasing at an alarming rate during the last two decades, affecting dramatically our ability to treat common infections. ${ }^{1}$ In addition, insufficient investment in antimicrobial therapies resulted in a lack of the discovery of new families of active molecules. ${ }^{1-3}$ This has led the World Health Organization (WHO) to raise the alarm against antimicrobial resistance and especially the resurgence of multi-drug resistant bacteria. It is particularly true for Gram-negative bacteria. ${ }^{3-4}$ The urgent need to develop new molecules as alternatives to conventional antibiotics has led to consider to use peptides with antimicrobial properties.

Antimicrobial peptides (AMPs) have a minimum inhibitory concentration (MIC) often in the range of a few $\mu \mathrm{M}$. Despite a strong antimicrobial activity at low concentrations, their mode of action in killing bacteria or in inhibiting bacterial growth remains not fully understood. ${ }^{5-6}$ Most AMPs are believed to interact with the membranes where they induce permeabilization. The subsequent lysis or damage to bacteria is then observed. ${ }^{7-8}$ It is generally accepted that AMPs can form transmembrane channels by self-aggregation or multimerization, ${ }^{9-10}$ leading to membrane permeabilization and bacterial death. ${ }^{7}$ The AMP activity on the membrane can be influenced by the parietal structures of the bacteria such as lipopolysaccharides or lipoteichoic acids and the presence of pili and other appendages. ${ }^{11-12}$ Indeed, previous works highlighted that external cell wall structures of bacteria act as permeability barriers allowing selective passage of nutrients and exclusion of harmful substances (e.g. antimicrobial agents). ${ }^{13-14}$ Also some non-lytic intracellular modes of action have been reported. ${ }^{15-16}$ Some antimicrobial peptides can modify and/or inhibit bacterial metabolism, i.e. nucleic acids and protein biosynthesis, cell division, cell wall and lipopolysaccharide biosynthesis. ${ }^{15,17-18}$

Among the AMPs, host defense peptides (HDPs) are emerging as excellent candidates for the development of new antibiotic strategies. In addition to their antimicrobial action, they exhibit 
67 less side effects than other AMPs. ${ }^{19-21}$ They are able to kill a broad spectrum of 68 microorganisms with a very low cytotoxicity to mammalian cells. Owing to a general nonspecific action, they have a low level of induced resistance. ${ }^{12,21}$ Moreover, some of them have a very interesting therapeutic potential because they can activate the immune system while inhibiting the inflammatory response. ${ }^{22-23}$ Peptides derived from the proteolysis of chromogranin A are of particular therapeutic interest, and particularly cateslytin. ${ }^{24-25}$ This fragment of chromogranin $\mathrm{A}$ is a linear HDP of 15 residues, and therefore very easy to synthesize for a minimal cost. ${ }^{24-25}$ Previous studies demonstrated the high efficiency of Dcateslytin (D-Ctl) against a broad spectrum of bacteria including E. coli. ${ }^{24}$ It is accepted that the first target of the AMP is the outer membrane of the bacterium. However, no particular attention was paid to the role of bacterial cell-wall structures on D-Ctl efficiency or possible modification of its mode of action from one bacterial strain to another one.

In the present study, we investigated the action of D-Ctl on two strains of E. coli: one is nude of any parietal structures, the other overexpresses only Type 1 fimbriae. ${ }^{26}$ Type 1 fimbriae are uniformly distributed on the bacterial surface, and they are known for their surface adherence on epithelial cells. The bacterial attachment allowed by these Type 1 fimbriae is a major factor in bacterial pathogenicity. ${ }^{27-29}$ The action and the possible influence of these parietal structures were analyzed with a physico-chemical point of view through morphological, nanomechanical, and spectroscopic analyses. This work was performed with a combination of epifluorescence microscopy, atomic force microscopy (AFM), and Fourier transform infrared spectroscopy in Attenuated total reflectance mode (ATR-FTIR). ${ }^{30-31}$ These techniques were combined to monitor in situ the mechanism of action and the damages caused by D-Ctl at several initial concentrations of bacteria and times of exposure. Indeed, beyond the determination of MIC that gives information on the inhibition of growth, it is important to investigate what can happen when a high amount of bacteria is initially present. ATR-FTIR 


\section{Q.1. Chemicals and synthetic peptide}

\subsection{Bacterial strain and culture conditions}

The bacterial models used in this study are Gram-negative Escherichia coli mutants called E2152 and E2146 kindly provided by Institut Pasteur from Paris. ${ }^{26}$ These isogenic strains

Ampicillin, kanamycin and phosphate saline buffer (PBS) were purchased from SigmaAldrich, France. D-cateslytin is a positively charged (5+) arginine-rich peptide with the following amino acid sequence: RSMRLSFRARGYGFRGPG. It was purchased from ProteoGenix (Schiltigheim, France, purity $>95 \%$ ). The peptides were stored at $-20^{\circ} \mathrm{C}$ as a stock solution at $1 \mathrm{~g} / \mathrm{L}$ in non-pyrogenic sterile water (Aqua B-Braun, Melsungen, Germany). Structures and physicochemical properties of cateslytin are reported in Figure S1 (see Supporting Information).

were constructed from Escherichia coli MG1655. These mutants are non-flagellated and are resistant to specific antibiotics (ampicillin, kanamycin, chloramphenicol and zeocin). Strain E2152 is devoted from the main E. coli parietal structures while strain E2146 constitutively expresses only the external Type 1 fimbriae. E2152 strain was selected as a reference. ${ }^{26}$ Bacterial stocks were maintained at $-80^{\circ} \mathrm{C}$. Bacteria were grown in Lysogeny Broth (LB, 
Miller, Fluka) at $25 \mathrm{~g} / \mathrm{L}$ in deionized water (Purelab Option, ELGA). All cultures were grown in a water bath at $37 \pm 1{ }^{\circ} \mathrm{C}$, and under continuous agitation at $160 \mathrm{rpm}$. After an overnight sub-culture (16 hours, with antibiotics, i.e. ampicillin and kanamycin), bacteria were cultivated in $25 \mathrm{~mL}$ of LB medium (without antibiotics) in $150 \mathrm{~mL}$ Erlenmeyer flasks with an initial optical density at $600 \mathrm{~nm}$ of $0.05 \pm 0.01$. The bacteria were taken at the end of the exponential phase when $\mathrm{OD}_{600}$ reaches the value of $0.50 \pm 0.02$.

\subsection{Growth curves and minimum inhibitory concentration (MIC) estimation}

The growth curves were obtained by measuring the optical density at $600 \mathrm{~nm}\left(\mathrm{OD}_{600}\right)$ with a Tecan Infinite M200 spectrometer during 24 hours on bacterial suspensions (volume $200 \mu \mathrm{L}$ ) put in a 96-well plate (Nunc) in the presence or not of D-Ctl in LB medium. The bacterial suspension was used either at $\mathrm{OD}_{600}$ value of 0.50 or diluted to values at 0.10 and 0.001 corresponding to $3.18 \pm 0.27 \times 10^{8}, 1.05 \pm 0.18 \times 10^{8}$ and $2.64 \pm 0.33 \times 10^{6} \mathrm{CFU} / \mathrm{mL}$, respectively. The measurements were performed at least in triplicate. The MIC of strain E2152 was estimated in LB medium by the two-fold serial dilution assay as described elsewhere. ${ }^{24}$ Briefly, the bacterial suspension was diluted to $\mathrm{OD}_{600}=0.001$ in a sterile $96-$ well plate (Nunc, suspension volume $200 \mu \mathrm{L}$ ). After $24 \mathrm{~h}$ of incubation at $37^{\circ} \mathrm{C}$ without or with DCtl at different concentrations, the bacterial growth was assessed by the measurement of $\mathrm{OD}_{600}$ using a Tecan Infinite M200.

\subsection{Suspensions for epifluorescence microscopy, infrared spectroscopy and AFM}

For epifluorescence and infrared spectroscopy analyses, the antimicrobial assays against planktonic E. coli were performed in duplicate in sterile 96-well plates (Nunc) in a final volume of $200 \mathrm{~mL}$. When the optical density of the bacterial culture reached an $\mathrm{OD}_{600}$ value of $0.50 \pm 0.02$, the suspension was diluted in $\mathrm{LB}$ to give an $\mathrm{OD}_{600}=0.10 \pm 0.01$. The 
necessary volumes of the stock solution of the peptide at $1 \mathrm{~g} / \mathrm{L}$ was spotted in the bacterial suspension to a final volume of $200 \mu \mathrm{L}$. Sterility and growth controls were sterile LB, and a bacterial suspension without peptide, respectively. The plate was incubated for 1,4 and 14 hours at $23 \pm 1^{\circ} \mathrm{C}$ in an air conditioned room.

For AFM in-situ experiments, the required volume of D-Ctl mother solution at $537 \mu \mathrm{M}(1$

$147 \mathrm{~g} / \mathrm{L}$ ) was added to $1 \mathrm{~mL}$ of bacterial suspensions with an $\mathrm{OD}_{600}$ of $0.50 \pm 0.02$ to reach final

148 concentrations of $0,8,40$ and $80 \mu \mathrm{g} / \mathrm{mL}$. Then suspensions were deposited into a 24-well

149 plates (Nunc) containing gold disks coated with amino-terminated thiol $\left(\mathrm{HS}-\mathrm{C}_{11}-\mathrm{NH}_{3} \mathrm{Cl}\right)$

150 purchased from Prochimia (Prochimia surfaces, Poland). Samples were incubated at $22 \pm 1^{\circ} \mathrm{C}$

151 for 1, 4 and 14 hours exposure times.

152

\subsection{Fluorescence optical microscopy and membrane status assays}

154 The bacteria shape and the integrity of the bacterial membrane were assessed using the 155 BacLight ${ }^{\mathrm{TM}}$ stain kit (L7012, Molecular Probes, Eugene, USA). The cell-wall permeability in 156 the absence and presence of the D-Ctl was examined according to a methodology described in 157 previous works. ${ }^{24,31}$ With this kit, bacteria with intact membranes exhibit green fluorescence 158 (Syto 9), while bacteria with damaged membranes show red fluorescence (propidium iodide, 159 PI). The bacterial suspensions were stained with the BacLight ${ }^{\mathrm{TM}}$ kit during 20 minutes in the 160 dark. Then the suspension was filtered onto a $0.22 \mu \mathrm{m}$ membrane, and the membrane was 161 rinsed with non-pyrogenic sterile water to eliminate excess dyes. The sample was mounted in 162 BacLight ${ }^{\mathrm{TM}}$ mounting oil as described by the instructions provided by the manufacturer. 163 Images were acquired with the $\times 100$ oil immersion objective of an Olympus BX51 164 microscope equipped with an Olympus XC50 camera. Both fluorescences were observed 165 using fluorescence filter cube U-MWIB3 (Olympus, excitation filter: BP 460-495 nm, 166 emission filter: LP $510 \mathrm{~nm})$. 


\subsection{ATR-FTIR spectroscopy}

ATR-FTIR spectra were recorded on a Bruker Vertex70v spectrometer equipped with a $\mathrm{KBr}$ beam splitter and a DTGS detector. Spectra recording and data processing were performed using the Bruker OPUS 7.5 software. The resolution of the single beam spectra was $4 \mathrm{~cm}^{-1}$. Two hundred scans were collected per spectrum corresponding to a 2-minutes accumulation time. All interferograms were Fourier processed using the Mertz phase correction and a Blackman-Harris three-term apodization function. A nine-reflection diamond ATR accessory (DurasamplIR $R^{\mathrm{TM}}$, SensIR Technologies, incidence angle: $45^{\circ}$ ) was used for acquiring spectra. No ATR correction was performed. ATR-FTIR spectra are shown with an absorbance scale corresponding to $\log \left(\mathrm{R}_{\text {reference }} / \mathrm{R}_{\text {sample }}\right)$, where $\mathrm{R}$ is the internal reflectance of the device. Measurements were performed at $22 \pm 1{ }^{\circ} \mathrm{C}$ in an air-conditioned room. One drop of the bacterial suspension in LB medium was put on the ATR crystal. The spectral background was removed by recording the spectrum of the LB medium free of bacteria (obtained by centrifugation at $7000 \mathrm{~g}$ during 5 minutes). Water vapor subtraction was performed when necessary. All spectra were baseline corrected at 1800 and $900 \mathrm{~cm}^{-1}$. FTIR measurements were performed at $22 \pm 1^{\circ} \mathrm{C}$ in an air-conditioned room.

\subsection{Bacteria drying procedure for AFM imaging}

Critical point drying (CPD) with $\mathrm{CO}_{2}$ was used for sample preparation in order to get images at the nanoscale of the bacterial cells subjected or not to D-Ctl at various concentrations and for several exposure times. Indeed, this technique is one of the most accurate to preserve the highly fragile three-dimensional structure of biological samples especially when they are difficult to observe in aqueous media. ${ }^{32-34}$ Gold slides incubated with bacterial samples were rinsed three times in baths of PBS for 5 minutes each. Then samples were dehydrated by 


\subsection{Atomic Force Microscopy characterizations}

immersion into 8 successive baths of water/ethanol mixtures (ratios of 90/10, 80/20, 70/30, $50 / 50,30 / 70,20 / 80,10 / 90,0 / 100$ ) for 10 minutes each and stored in pure ethanol before CPD treatment. The CPD procedure is carried out using a homemade device ${ }^{35}$, and according to 5 successive steps: (1) samples are placed into an autoclave with $250 \mu \mathrm{L}$ of pure ethanol onto each samples; (2) the autoclave is filled and pressurized with liquid $\mathrm{CO}_{2}$ for 30 minutes up to 90 bars at $30^{\circ} \mathrm{C}$; (3) the autoclave is heated for 20 minutes up to $45^{\circ} \mathrm{C}$; (4) water and ethanol residues were extracted from the samples through the supercritical $\mathrm{CO}_{2}(5)$ depressurization and decrease of temperature from $45^{\circ} \mathrm{C}$ to the ambient conditions during 30 minutes. At the end of these steps, the samples were taken out of the autoclave and the samples were stored in petri dishes tightly closed to prevent absorption of water in the samples.

Morphology images (dried samples) and in-situ monitoring of bacterial cells mechanical properties (living bacteria) were performed using the PeakForce tapping ${ }^{\mathrm{TM}}$ mode, with a Bioscope Resolve (Bruker Nano Surface, Bruker France SAS, Palaiseau, France). Silicon nitride cantilevers with conical tips were purchased from Bruker (NPG-10, Bruker France SAS, Palaiseau, France) with a spring constant of about $0.35 \mathrm{nN} / \mathrm{nm}$. The applied force between the tip and the samples surface was carefully controlled and minimized at $\sim 0.250$ $\mathrm{nN}$. All images were acquired with a resolution of 512 pixels by 512 pixels and a scan rate of 1.0 Hz. AFM images with scan sizes of $10 \mu \mathrm{m} \times 10 \mu \mathrm{m}$ and $5 \mu \mathrm{m} \times 5 \mu \mathrm{m}$ were then analyzed with Nanoscope Analysis for extracting roughness, thickness, and general morphology.

Mechanical properties of bacterial cells were investigated in LB medium using a MFP3D-BIO instrument (Asylum Research Technology, Oxford Instrument, Manheim, Germany) using silicon nitride cantilevers with conical tips (OMCL-TR400PSA-3, Olympus, Japan) with a spring constant of about $10-15 \mathrm{pN} / \mathrm{nm}$. The bacterial stiffness was calculated by analyzing the 
217 force-indentation curves according to the Sneddon model. ${ }^{36-37}$ In this model, the Young 218 modulus is related to the applied force according to the equation given below:

$$
F=\frac{2 E \cdot \operatorname{Tan}(\alpha)}{\pi\left(1-v^{2}\right)} \mathrm{R}^{1 / 2} \delta^{2} \cdot f_{\mathrm{BECC}}
$$

where $\delta$ is the indentation depth, $v$ the Poisson coefficient, $\alpha$ the semi-top angle of the tip and

$f_{\mathrm{BECC}}$ is the bottom effect cone correction function that take into account the presence of the substrate stiffness. ${ }^{37}$ All mechanical measurements were determined using an automatic

Matlab algorithm described elsewhere, ${ }^{38}$ and the average values given in this work were calculated from at least 2000 force curves.

\subsection{Bacterial trapping and monitoring by fast scanning microscopy}

Bacterial suspensions were injected through a syringe to a homemade nanofluidic chip containing bacterial traps ${ }^{39}$ and directly mounted on a custom integration of a Dimension Fast Scan AFM on an inverted optical microscope as described elsewhere. ${ }^{40}$ By creating a pressure difference across the nanofluidic traps, the bacteria were attracted and physically immobilized into the traps for further AFM analyses. Morphology as well as mechanical properties of immobilized bacteria were obtained in LB medium using PeakForce QNM® mode using a ScanAsyst@-Fluid cantilever with $1.6 \mathrm{nN} \cdot \mathrm{nm}^{-1}$ spring constant. During the bacterial monitoring procedure, the pressure in the microfluidic chamber underneath the membrane was kept between 20 and 100 mbar below atmospheric pressure.

\section{Results and Discussion}

\subsection{Effect of D-Ctl on the bacterial growth of $E$. coli strains}

The minimal inihibitory concentration (MIC) was determined at $8 \mu \mathrm{g} / \mathrm{mL}$ for the E2146 strain. ${ }^{24}$ The MIC of E2152 was estimated in the same range, i.e. between 5 and $10 \mu \mathrm{g} / \mathrm{mL}$ in 
this work. Hereafter, MIC refers to the minimal inhibitory concentration for E2146. The

242 growth of both bacteria at different initial $\mathrm{OD}_{600}$ was monitored by measuring the $\mathrm{OD}_{600}$ as a

243 function of time for 24 hours (Figure 1). In absence of D-Ctl the middle of exponential growth phase is reached after 13-14, 9 and 9 hours for both strains at initial $\mathrm{OD}_{600}$ set at $0.001,0.1$ and 0.5 , respectively. The stationary growth phase begins after 24 hours for an initial $\mathrm{OD}_{600}$ set at 0.001 , and it was not reached for suspensions with initial $\mathrm{OD}_{600}$ set at 0.1 and 0.5 , only pseudo-plateaus are observed. The growth curves of bacteria incubated for 24 hours with D-Ctl at the MIC show several features as a function of the initial concentration of bacteria (Figure 1). At initial $\mathrm{OD}_{600}$ set at 0.001 , no growth of E2152 was recorded during 23 hours, whereas a significant bacterial growth started after 10 hours for strain E2146. At initial $\mathrm{OD}_{600}$ set at 0.01 , bacteria grew during $\sim 6$ hours and then a slightly descending plateau was reached, suggesting the stop of the multiplying process. When the initial number of bacteria was higher, i.e. $\mathrm{DO}_{600}=0.50$, the $\mathrm{OD}_{600}$ after 24 hours of culture were below those of control cultures. The bacterial growth continued at a slower rate than in control culture for strain E2152. In presence of D-Ctl at $5 \times \mathrm{MIC}$ and $10 \times \mathrm{MIC}$, no significant bacterial growth was measured during 24 hours whatever the initial concentration of bacteria. These results demonstrated the existence of a concentration threshold from which D-Ctl totally inhibits the bacterial growth for a defined number of cells. Besides, the inhibitory and even the bactericidal activity of D-Ctl also depend on the initial number of bacterial cells exposed. To sum-up, these results strongly suggested that E2146 seems to tolerate D-Ctl better than 2152 .

\subsection{Bacterial membrane status and morphology under D-Ctl treatment}

E2152 and E2146 bacteria were stained with the BacLight ${ }^{\mathrm{TM}}$ kit at the D-Ctl concentrations and exposure times previously described. Figure 2 and Figure 3 show representative images for E2152 and E2146, respectively. Except for few of them, the bacteria of both strains grown 
without D-Ctl were green showing rod-shaped bacteria with non-damaged membranes. The average lengths were estimated and are gathered in Table 1. Both bacteria strains have the same range of average length, i.e. $\sim 2.3$ to $\sim 2.7 \mu \mathrm{m}$ whatever the time of culture. Many bacteria were dividing, and here we did not discriminate bacteria just divided (length $\sim 1.5$ $\mu \mathrm{m}$ ) from those that were dividing (lengths from $\sim 2.0$ to $\sim 3 \mu \mathrm{m}$ ).

Table 1: Average length $(\mu \mathrm{m})$ of bacteria in presence or not to antimicrobial peptide D-Ctl (red: average length for red bacteria in the images; green: average length for green bacteria in the images).

\begin{tabular}{|c|c|c|c|c|c|}
\hline & Time & Without D-Ctl & MIC & $5 \times \mathrm{MIC}$ & $10 \times \mathrm{MIC}$ \\
\hline \multirow{3}{*}{$\frac{1}{2}$} & $1 \mathrm{hr}$ & $2.7 \pm 0.6$ & $2.9 \pm 0.5$ & $2.3 \pm 0.3$ & $2.6 \pm 0.4$ \\
\hline & $4 \mathrm{hrs}$ & $2.7 \pm 0.6$ & $\begin{array}{c}3.6 \pm 1.0(\mathrm{red}) \\
2.6 \pm 0.4 \text { (green) }\end{array}$ & $2.9 \pm 0.8$ & $2.5 \pm 0.4$ \\
\hline & $14 \mathrm{hrs}$ & $2.6 \pm 0.4$ & $\begin{array}{c}3.3 \pm 0.8(\text { red }) \\
2.6 \pm 0.5(\text { green })\end{array}$ & $3.2 \pm 0.5$ & - \\
\hline \multirow{3}{*}{ 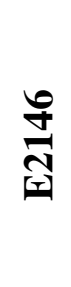 } & $1 \mathrm{hr}$ & $2.3 \pm 0.4$ & $2.7 \pm 0.2$ & $2.9 \pm 0.4$ & $2.6 \pm 0.4$ \\
\hline & $4 \mathrm{hrs}$ & $2.4 \pm 0.4$ & $\begin{array}{c}2.9 \pm 0.7(\text { red }) \\
2.3 \pm 0.3(\text { green })\end{array}$ & $2.6 \pm 0.4$ & $2.6 \pm 0.3$ \\
\hline & $14 \mathrm{hrs}$ & $2.3 \pm 0.4$ & $\begin{array}{c}4.1 \pm 2.7(\mathrm{red}) \\
3.1 \pm 1.7 \text { (green) }\end{array}$ & $2.6 \pm 0.4$ & $2.6 \pm 0.4$ \\
\hline
\end{tabular}

When E. coli E2152 was exposed to D-Ctl at the MIC, almost all bacteria appeared red, and their average size slightly increased at all the contact times. Only a few of them were green showing intact membranes (Figures $\mathbf{2 b}, \mathbf{f}, \mathbf{j}$ ), and their shape and size did not change significantly with respect to bacteria not exposed to D-Ctl (control experiment). The average size was increased after 4 and 14 hours of exposure to D-Ctl at the MIC for red bacteria. The higher standard deviation for length measurements showed a non-homogenous behavior of the bacteria in front of D-Ctl (Table 1). The occurrence of a few filamentous cells can be noticed, and they were up to $\sim 25 \mu \mathrm{m}$ long after 14 hours of contact with D-Ctl. In addition to the increase of the permeability to PI, some bacteria were highly stressed showing it by the 
inhibition of the division of the cells. For concentrations of D-Ctl at $5 \times \mathrm{MIC}$ and $10 \times \mathrm{MIC}$, all bacteria were red, showing damaged membranes. At 10×MIC and after 14 hours of contact, no bacteria were observed. This result suggested that almost all the bacteria were lysed by the action of D-Ctl or they were too much damaged to resist to the mechanical filtration. For $5 \times \mathrm{MIC}$ and $10 \times \mathrm{MIC}$ of D-Ctl, few bacteria become filamentous with lengths up to $18 \mu \mathrm{m}$, the average length of the remaining bacteria were close to those in absence of the peptide.

When E. coli E2146 was submitted to D-Ctl at the MIC, most of bacteria were red, but a nonnegligible number of bacteria remained green meaning that their membrane was not damaged (Figure 3b, f, j). The average shape and length of the green bacteria were close to each other and close to those observed for the bacteria in the control experiment whatever the time of exposure to D-Ctl. After 4 and 14 hours of contact with D-Ctl, red bacteria (i.e. with damaged membranes) had a higher average length with a high distribution of lengths, especially after 14 hours of contact with D-Ctl $(4.1 \pm 2.7 \mu \mathrm{m}$, Table 1, Figure 3f, j). A few bacteria developed long filamentous shapes, their length reached up to $\sim 9 \mu \mathrm{m}$ after $4 \mathrm{~h}$ and $24 \mu \mathrm{m}$ after 14 hours of contact with D-Ctl indicating that the stress induced by the presence of D-Ctl was very high. Bacteria submitted to D-Ctl at $5 \times \mathrm{MIC}$ and $10 \times \mathrm{MIC}$ were almost all red, only a few of them were observed green for an exposure of 4 hours at $5 \times \mathrm{MIC}$. The average length increased slightly (less than $0.6 \mu \mathrm{m}$ ). In contrast of all the other conditions of D-Ctl exposure, the PI staining of E2146 at D-Ctl concentrations of $5 \times \mathrm{MIC}$ and $10 \times \mathrm{MIC}$ was not homogenous along the cell (Figure 3c,d,g,h,k,l). The fluorescence was highly concentrated at specific areas of the bacteria making to appear bright orange-red dots inside the bacteria. Propidium iodide stains both RNA and DNA. This non-homogenous staining through the whole bacteria implies that nucleic acids were probably aggregated upon the presence of DCtl. 
A closer look on the bacterial morphology was performed using AFM to decipher possible cell wall damages at the nanoscale. Several areas of $10 \times 10$ and $5 \times 5 \mu \mathrm{m}^{2}$ were investigated and representative images were collected, and they are reported in Figure 4 and Figure 5. In absence of D-Ctl, E2152 exhibits a smooth and rod-shaped structure with an average length of about $1.6 \pm 0.4 \mu \mathrm{m}$ for a width of $0.8 \pm 0.1 \mu \mathrm{m}$, which are in accordance with epifluorescence images. The height profiles (Figures S2 - S9) showed bacterial diameter of c.a. $650 \mathrm{~nm}$. When E2152 cells are exposed to D-Ctl, the rod-shaped structure is maintained but the cell size was increased. Indeed, the average length and width are increased up to $2.3 \pm 0.6 \mu \mathrm{m}$ and $1.0 \pm 0.2 \mu \mathrm{m}$, respectively. Such increase in size is also confirmed by the height profiles that evidenced bacterial diameters reaching from $650 \mathrm{~nm}$ up to $750 \mathrm{~nm}$ (Figure 6a). D-Ctl activity seems to inflate bacterial cells but no major damages as pores or important roughness have been observed with AFM even though the BacLight ${ }^{\mathrm{TM}}$ assays evidenced that almost all bacteria exposed to D-Ctl exhibited damaged membranes.

In absence of D-Ctl, E2146 exhibits a smooth and rod-shaped structure with an average length of about $1.4 \pm 0.2 \mu \mathrm{m}$ for a width of $0.7 \pm 0.1 \mu \mathrm{m}$ that are in accordance with epifluorescence images. The height profiles (Figure 6b) showed bacterial diameter of c.a. $600 \mathrm{~nm}$. When E2146 cells are exposed to D-Ctl, an evolution of bacterial morphology similar to E2152 was observed. The rod-shaped structure is maintained but the cell size was increased with average length and width reached up to $2.5 \pm 0.6 \mu \mathrm{m}$ and $1.0 \pm 0.3 \mu \mathrm{m}$, respectively. The analyses of height profiles (Figure 6) revealed an increase of the bacterial diameter from $600 \mathrm{~nm}$ up to $850 \mathrm{~nm}$. As previously observed for E2152, bacterial cells seem to be also inflated without major detectable damages.

One can emphasize that permeabilization activity of D-Ctl is increased with concentration and exposure time but the rod-shaped structure of non-lysed treated cells is maintained whatever exposure time and D-Ctl concentration. In addition, the damages revealed by AFM could be 


\section{B.3. Evolution of bacterial stiffness during D-Ctl treatment} Bacterial stiffness of E2152 and E2146 was monitored during 24 hours under D-Ctl concentrations of 0 and $40 \mu \mathrm{g} / \mathrm{mL}(5 \times \mathrm{MIC})$ and reported in Figure 7a, b. In absence of D-

associated to high membrane weakening that maybe enhanced by the drying process (Figure S10). Non-lysed treated cells are inflated upon D-Ctl exposure and the bacterial swelling is much higher in presence of Type 1 fimbriae. The membrane permeability and bacterial shape are intimately connected to the cell-wall mechanical features. In this way, the permeabilization or membrane activity of $\mathrm{D}-\mathrm{Ctl}$ can be investigated through the elastic properties of the bacterial cell wall by force spectroscopy. Ctl, Figure 7 shows that the bacterial stiffness of E2152 and E2146 remain very stable during 24 hours with values of c.a. 600 and $300 \mathrm{kPa}$, respectively. These values are in agreement with previous mechanical analyses of the two bacterial strains. ${ }^{26}$ When the bacterial cells are exposed to D-Ctl at $40 \mu \mathrm{g} / \mathrm{mL}$, the bacterial stiffness shows two different behaviors according to the bacterial strains. Indeed, the bacterial stiffness of E2152 slightly increased from c.a. $600 \mathrm{kPa}$ up to $900 \mathrm{kPa}$ while it decreased from c.a. $300 \mathrm{kPa}$ down to $40 \mathrm{kPa}$ for E2146. Here, the impact of D-Ctl on the bacterial stiffness is highly influenced by the presence of the of Type 1 fimbriae structures. In the absence of Type 1 fimbriae, a stiffening of about $30 \%$ is observed over 24 hour-treatment whereas a dramatic softening of about $85 \%$ when Type 1 fimbriae are expressed.

The mechanical behavior of E2152 under D-Ctl treatment seemed counterintuitive in respect with the membrane permeabilization supported by the BacLight ${ }^{\mathrm{TM}}$ assays. However, mechanical stiffening under AMP has been already reported for huge peptides accumulation at bacterial envelope concomitantly to its permeabilization. ${ }^{31,41-42}$ The mechanical behavior of E2146 under D-Ctl treatment is in good agreement with previous observations ${ }^{24}$ that have 
evidenced a reduction of bacterial stiffness by a factor of 3 with respect to the untreated bacteria. This dramatic evolution of bacterial stiffness was explained by membrane permeabilization as supported by the BacLight ${ }^{\mathrm{TM}}$ assays and should reflect the loss of cytosol that led to bacterial lysis and death. ${ }^{24,43-44}$ Here, we clearly evidenced unexpected different mechanical effects of D-Ctl on E. coli cells constitutively expressing or not the Type 1 fimbriae. How such opposite mechanical effects can be explained, and what is the influence of the bacterial external structures on the D-Ctl activity?

To address these questions, and to understand the molecular origin in such differences of mechanical effects, the evolution of the biochemical fingerprints of D-Ctl and the two bacterial strains were monitored by Fourier transform infrared spectroscopy (ATR-FTIR). Indeed, ATR-FTIR allows the investigation of physiological, biochemical and conformational changes of D-Ctl.

\subsection{Infrared spectral fingerprints of the bacteria submitted or not to D-Ctl}

IR-ATR spectra from both E. coli suspensions in presence or not of D-Ctl are shown in Figure 8 and Figure 9. One should notice that the background for every spectrum presented here is the supernatant free of bacteria corresponding to the suspension under study. Therefore, the spectra are representative for the remaining bacteria only, the contribution of the medium being removed.

The spectra of the bacteria cultured without D-Ctl showed the specific features of Gramnegative bacteria. ${ }^{24,30,45}$ Usual signatures of the biochemical components of bacterial cells, i.e. proteins (P), nucleic acids (NA), phospholipids (PL) and polysaccharides (PS) are present (main assignments are given in Figures 8a and Figure 9a). The overall intensities of the whole spectra increased in as a function of the increase of the time of culture in accordance with the growth curves recorded with the same conditions (Figure 1). 
When E2152 was submitted to D-Ctl for 1 and 4 hours, the general spectral signatures of the spectra were preserved with respect to those of the bacteria of the control experiment for all three concentrations of D-Ctl. However, the spectra stayed at the same level of intensities showing, in accordance with growth curves, that at least the growth was very quickly stopped (Figure 8). After 14 hours of D-Ctl exposure to bacteria, the signal-to-noise ratio of the spectra were very low, suggesting a very low concentration of bacteria in those suspensions. After 14 hours of D-Ctl exposure, the intensities of the bands at $\sim 1240$ and $1085 \mathrm{~cm}^{-1}$ mainly assigned to $\mathrm{PO}_{2}$ stretchings of nucleic acids were very low, suggesting that the metabolic activity was also very low.

One can emphasize that the contribution of PLs to the global spectral profile is low and the loss of the latter is negligible since no cell debris showing bacterial lysis has been observed either in AFM or in epifluorescence microscopy.

When E2146 was exposed to D-Ctl at the MIC, the general features of the spectra were similar at every time of exposure to D-Ctl, looking as those of bacteria from the control experiment (Figure 9b). In addition, the whole intensity of the spectrum after 1 hour of the DCtl exposure was similar to the control experiment after 1 hour of culture. The whole intensities of the spectra did not change drastically suggesting that bacteria did not grow upon the exposure to D-Ctl. However, bands assigned mainly to nucleic acids around 1230 and $1086 \mathrm{~cm}^{-1}$, were present. They suggested that the metabolic activity was maintained at least partially for 14 hours at the MIC. The features of the spectra from the bacteria after contact with D-Ctl at $5 \times$ and $10 \times$ MIC were different (Figures 9c, d). Indeed, bands at $\sim 1621$ and $\sim 1526 \mathrm{~cm}^{-1}$ newly appeared in the region of amide bands from proteins and peptides. These bands are assigned to $\beta$-sheets. It has been shown that $\mathrm{D}$-Ctl, which is unstructured in solution, forms antiparallel $\beta$-sheets that aggregate at the surface of negatively charged bacterial mimetic membranes. ${ }^{9}$ Therefore, it can be suggested that D-Ctl accumulated on 
or/and in the bacteria forming such aggregates on or/and in the bacteria. The spectral region between 1250 and $1000 \mathrm{~cm}^{-1}$ was very different with respect to the control spectra. The general shape of these bands, mainly assigned to $\mathrm{PO}_{2}$ stretchings of nucleic acids, were less resolved as compared to the control spectra and their intensities relative to amide bands were lower (Figures 9c, d). The structure and the amount of nucleic acids were affected by the presence of D-Ctl. This suggested an intracellular action of D-Ctl when its concentration was very high. Altogether, spectroscopic analyses suggested that D-Ctl activity led to a dramatic decrease in metabolism of both bacterial strains until a total break depending on AMP concentration. Such interruption in bacterial metabolism seemed to be enhanced when bacterial cell-wall are decorated with type-1 fimbriae.

\subsection{Impact of parietal structures on the D-Ctl mode of action}

As regarding the results obtained from both microbiological and physico-chemical investigations, one can notice the occurrence of two different behaviors in D-Ctl activity as a function of the D-Ctl concentration (at MIC and $\geq 5 \mathrm{MIC}$ ). D-Ctl antibacterial activity is not related to the initial bacterial concentration considered for both strains, i.e. the concentrations are very similar whatever the strain for a given $\mathrm{OD}_{600}$. Besides, this activity is very different between the nude cell-wall and the Type 1 fimbriae decorated bacteria.

In details, when both bacterial strains are exposed to D-Ctl at MIC, almost all membranes are damaged after 4 and 14 hours without any pore formation upon AFM observations. However, the membranes are more impacted for the nude cell-wall bacteria than those with the Type 1 fimbriae. Besides, BacLight ${ }^{\mathrm{TM}}$ assays and ATR-FTIR measurements supported that their metabolism is not totally interrupted but disturbed. Indeed, E2146 bacteria appeared filamentous; the presence of D-Ctl disrupted the cell division. On the contrary very few cells of E2152 appeared filamentous. Both strains bacteria appeared inflated with higher diameter 
size and continued to elongate but failed to septate. This can be subsequent to the blocking of DNA replication, interruption in chromosome segregation, or inhibition of cell division. ${ }^{46-47}$ One can notice that there is no significant evolution of bacterial stiffness at MIC concentration as evidenced in Figure 7d while important modifications occurred at higher D$\mathrm{Ctl}$ concentrations as reported in Figure 7a, b. These observations suggested that the D-Ctl action on bacterial stiffness strongly depends on the occurrence of parietal structures (i.e. here type-I fimbriae). This assumption is supported by the progressive bacterial stiffness drop of E2146 when D-Ctl concentration was increased from MIC to $5 \times$ MIC (Figure 7d). On can notice that a slight evolution in bacterial stiffness has been evidenced for E2152 strain (data not shown) in accordance with the one observed for high D-Ctl concentrations reported in

\section{Figure 7a, b.}

At $5 \times \mathrm{MIC}$ and $10 \times \mathrm{MIC}$, both bacterial strains did not grow anymore. After 14 hours of exposure with D-Ctl, the ATR-FTIR spectroscopic investigations revealed that the amount of nucleic acids for E2152 is also low with respect to the protein amount, suggesting the stop of the metabolic activity. Concerning E2146, the cells have mostly damaged membranes. However, the staining was not homogenous inside the bacteria, bright red-orange dots occurred within the cells. It is concomitant with aggregation of D-Ctl with the formation of $\beta$ sheets confirmed by ATR-FTIR investigations. As PI is a nucleic acids dye, one can suggest that the bacterial nucleic acids aggregated upon the binding of D-Ctl. Previous studies have shown that cationic AMP with antiparallel $\beta$-sheets and/or rich in arginine can bind nucleic acids. ${ }^{48-50}$ The membrane is not the only target of the peptide as it is shown here for E2146. Conversely, E2152 bacteria staining is homogeneous whatever the exposure time suggesting that D-Ctl remained at the bacterial cell-wall. The constitutive expression of Type 1 fimbriae with respect to the nude cell-wall strain can weaken the outer membrane and thus can facilitate the D-Ctl translocation. Therefore, D-Ctl activity could be characterized by the 
damaging of the outer membrane via electrostatic interactions followed by the peptide translocation. Further intracellular translocation results in the decrease or the inhibition of the acid nucleic synthesis. It is evidenced by the bacterial filamentation at the MIC mainly for E2146 and by the aggregation of nucleic acids at the highest concentrations of D-Ctl.

The small differences observed in the bacterial growth for increasing concentration of D-Ctl, are supported by macroscopic effects such as modifications of the bacterial suspension turbidity. Indeed, Figure 10 showed drastic effects of D-Ctl increasing concentration on suspension turbidity and bacterial aggregation. For E2152 bacteria, the increase of D-Ctl concentration led to an important bacterial aggregation at the bottom of the spectrophotometer cuvettes delimited by the white dashed lines. For E2146 bacteria, the effect of increasing DCtl concentration is lower on bacterial aggregation and the bacterial suspension became less and less cloudy suggesting a more important bacteriolytic activity. These results are in agreement with the difference in bacterial surface charge density of the two strains. The surface of E2152 is almost 6 times more negatively charged than E2146 according to previous studies that highlighted surface charge density of about $-170 \mathrm{mM}$ and $-30 \mathrm{mM}$ for E2152 and E2146, respectively. ${ }^{26}$ Such differences should lead to larger interactions and accumulation of D-Ctl onto E2152 bacterial cell wall than the latter onto E2146. Further analyses combining zeta potential and dynamic light scattering could be more relevant to decipher the molecular mechanism behind this macroscopic phenomenon. Besides, overexpression of Type I fimbriae could significantly weaken the bacterial outer-membrane and facilitate its permeabilization by the antimicrobial peptides. This phenomenon has been previously reported for LPS modifications/expression modulation that impact on the bacterial resistance/tolerance to antimicrobial peptides and antibiotics. ${ }^{51-52}$

\section{Conclusion}


In the present study, we report a systematic analysis of nanomechanical and spectrochemical properties related to the antibacterial mechanism of action on two E. coli strains expressing or not Type 1 fimbriae exposed to different D-Ctl doses and during several exposure periods. It is found that depending of D-Ctl concentration, bacterial stiffness is dramatically modified concomitantly to major membrane damages and important changes in the spectral fingerprint of the bacteria. However, no pore formation has been observed while all bacterial membranes were permeabilized under high D-Ctl concentrations. In case of the occurrence of fimbrial structures, an intracellular mode of action was shown also. Our results evidenced that D-Ctl activity is highly impacted by the cell-wall external structures and surface properties such as Type 1 fimbriae leading or not to macroscopic aggregation. In this way, as it was reported on the LPS modification, the modulation of parietal structures expressions could have a strong impact on the bacterial resistance/tolerance to antimicrobial peptides and therefore can be a strategy used by bacteria to bypass the immune defenses.

\section{Acknowledgements}

The authors thank C. Beloin from Institut Pasteur - Paris for critical reading of the manuscript, fruitful help and discussion on microbiological aspects of our work. FQ and GF thank the Spectroscopy and Microscopy Service Facility (SMI) of LCPME (Université de Lorraine-CNRS - http://www.lcpme.cnrs-nancy.fr). GEF and OP acknowledge support by the Swiss national science foundation under grant number 205320_152675.

\section{Supporting Information}


Structures and physicochemical properties of D-cateslytin and scheme of bacterial strains cell wall (Figure S1), AFM imaging and height profiles of reference bacteria E2152 in absence of D-Ctl and performed in air after $\mathrm{CO}_{2}$ critical point drying (Figure S2), AFM imaging and height profiles of reference bacteria E2152 in presence of D-Ctl at MIC concentration and performed in air after $\mathrm{CO}_{2}$ critical point drying (Figure S3), AFM imaging and height profiles of reference bacteria E2152 in presence of D-Ctl at $5 \times$ MIC concentration and performed in air after $\mathrm{CO}_{2}$ critical point drying (Figure S4), AFM imaging and height profiles of reference bacteria $\mathrm{E} 2152$ in presence of D-Ctl at $10 \times \mathrm{MIC}$ concentration and performed in air after $\mathrm{CO}_{2}$ critical point drying (Figure S5), AFM imaging and height profiles of E2146 bacteria in absence of D-Ctl and performed in air after $\mathrm{CO}_{2}$ critical point drying (Figure S6), AFM imaging and height profiles of E2146 bacteria in presence of D-Ctl at MIC concentration and performed in air after $\mathrm{CO}_{2}$ critical point drying (Figure S7), AFM imaging and height profiles of E2146 bacteria in presence of D-Ctl at $5 \times$ MIC concentration and performed in air after $\mathrm{CO}_{2}$ critical point drying (Figure S8), AFM imaging and height profiles of E2146 bacteria in presence of D-Ctl at $10 \times \mathrm{MIC}$ concentration and performed in air after $\mathrm{CO}_{2}$ critical point drying (Figure S9 Evolution with time of stiffness ratio for E2152 and E2146 in presence of D-Ctl at $40 \mu \mathrm{g} / \mathrm{mL}$ (Figure S10), In-situ monitoring of D-Ctl activity on E2146 bacteria (Fast scanning of trapped single bacterium) (Figure S11), AFM imaging of E2146 bacteria in absence and in presence of D-Ctl at $5 \times$ MIC concentration and performed in air after gentle nitrogen drying (Figure S12), and AFM imaging of E2152 bacteria in absence and in presence of D-Ctl at $5 \times$ MIC concentration and performed in air after gentle nitrogen drying (Figure S13). The Supporting Information is available free of charge on the ACS Publications website. 
1. Williams, K. J.; Bax, R. P., Challenges in developing new antibacterial drugs. Curr. Opin. Investig. Drugs 2009, 10 (2), 157-63. Have We Come from, Where Do We Go? Antibiotics (Basel) 2019, 8 (2), 45.

3. Silver, L. L., Challenges of antibacterial discovery. Clin. Microbiol. Rev. 2011, 24 (1), 540 71-109.

4. Tacconelli, E.; Carrara, E.; Savoldi, A.; Harbarth, S.; Mendelson, M.; Monnet, D. L.; Pulcini, C.; Kahlmeter, G.; Kluytmans, J.; Carmeli, Y.; Ouellette, M.; Outterson, K.; Patel, J.; Cavaleri, M.; Cox, E. M.; Houchens, C. R.; Grayson, M. L.; Hansen, P.; Singh, N.; Theuretzbacher, U.; Magrini, N.; Group, W. H. O. P. P. L. W., Discovery, research, and development of new antibiotics: the WHO priority list of antibiotic-resistant bacteria and tuberculosis. Lancet Infect. Dis. 2018, 18 (3), 318-327.

5. Corrêa, J. A. F.; Evangelista, A. G.; Nazareth, T. d. M.; Luciano, F. B., Fundamentals on the molecular mechanism of action of antimicrobial peptides. Materialia 2019, 8, 100494.

6. Kumar, P.; Kizhakkedathu, J. N.; Straus, S. K., Antimicrobial Peptides: Diversity, Mechanism of Action and Strategies to Improve the Activity and Biocompatibility In Vivo. Biomolecules 2018, 8 (1).

7. Shai, Y., Mode of action of membrane active antimicrobial peptides. Biopolymers 2002, 66 (4), 236-48.

8. Wenzel, M.; Chiriac, A. I.; Otto, A.; Zweytick, D.; May, C.; Schumacher, C.; Gust, R.; Albada, H. B.; Penkova, M.; Kramer, U.; Erdmann, R.; Metzler-Nolte, N.; Straus, S. K.; Bremer, E.; Becher, D.; Brotz-Oesterhelt, H.; Sahl, H. G.; Bandow, J. E., Small cationic antimicrobial peptides delocalize peripheral membrane proteins. Proc. Natl. Acad. Sci. U. S. A. 2014, 111 (14), E1409-18.

9. Jean-Francois, F.; Castano, S.; Desbat, B.; Odaert, B.; Roux, M.; Metz-Boutigue, M. H.; Dufourc, E. J., Aggregation of cateslytin beta-sheets on negatively charged lipids promotes rigid membrane domains. A new mode of action for antimicrobial peptides? Biochemistry 2008, 47 (24), 6394-402.

10. van der Weide, H.; Brunetti, J.; Pini, A.; Bracci, L.; Ambrosini, C.; Lupetti, P.; Paccagnini, E.; Gentile, M.; Bernini, A.; Niccolai, N.; Jongh, D. V.; Bakker-Woudenberg, I.; Goessens, W. H. F.; Hays, J. P.; Falciani, C., Investigations into the killing activity of an antimicrobial peptide active against extensively antibiotic-resistant $\mathrm{K}$. pneumon iae and $\mathrm{P}$. aeruginosa. Biochim. Biophys. Acta, Biomembr. 2017, 1859 (10), 1796-1804.

568 11. Malanovic, N.; Lohner, K., Gram-positive bacterial cell envelopes: The impact on the 569 activity of antimicrobial peptides. Biochim. Biophys. Acta, Biomembr. 2016, 1858 (5), 936-46.

570 12. Joo, H. S.; Fu, C. I.; Otto, M., Bacterial strategies of resistance to antimicrobial 571 peptides. Philos. Trans. R. Soc., B 2016, 371 (1695). 
13. Silhavy, T. J.; Kahne, D.; Walker, S., The bacterial cell envelope. Cold Spring Harb Perspect. Biol. 2010, 2 (5), a000414.

14. Miller, S. I., Antibiotic Resistance and Regulation of the Gram-Negative Bacterial Outer Membrane Barrier by Host Innate Immune Molecules. mBio 2016, 7 (5), e01541-16.

15. Le, C. F.; Fang, C. M.; Sekaran, S. D., Intracellular Targeting Mechanisms by Antimicrobial Peptides. Antimicrob. Agents Chemother. 2017, 61 (4), e02340-16.

16. Scocchi, M.; Mardirossian, M.; Runti, G.; Benincasa, M., Non-Membrane Permeabilizing Modes of Action of Antimicrobial Peptides on Bacteria. Curr. Top. Med. Chem. 2016, 16 (1), 76-88.

17. Brogden, K. A., Antimicrobial peptides: pore formers or metabolic inhibitors in bacteria? Nat. Rev. Microbiol. 2005, 3 (3), 238-50.

18. Jackson, K. E.; Miller-White, T., The intracellular target of the antimicrobial peptide thanatin. J. Immunol. 2018, 200 (1 Supplement), 170.17-170.17.

19. Nijnik, A.; Hancock, R., Host defence peptides: antimicrobial and immunomodulatory activity and potential applications for tackling antibiotic-resistant infections. Emerg. Health Threats J. 2009, 2, e1.

20. Hancock, R. E.; Haney, E. F.; Gill, E. E., The immunology of host defence peptides: beyond antimicrobial activity. Nat. Rev. Immunol. 2016, 16 (5), 321-34.

21. Gupta, S.; Bhatia, G.; Sharma, A.; Saxena, S., Host defense peptides: An insight into the antimicrobial world. J. Oral Maxillofac. Pathol. 2018, 22 (2), 239-244.

22. Hemshekhar, M.; Anaparti, V.; Mookherjee, N., Functions of Cationic Host Defense Peptides in Immunity. Pharmaceuticals (Basel) 2016, 9 (3).

23. Schuerholz, T.; Brandenburg, K.; Marx, G., Antimicrobial peptides and their potential application in inflammation and sepsis. Crit. Care 2012, 16 (2), 207.

24. Zaet, A.; Dartevelle, P.; Daouad, F.; Ehlinger, C.; Quiles, F.; Francius, G.; Boehler, C.; Bergthold, C.; Frisch, B.; Prevost, G.; Lavalle, P.; Schneider, F.; Haikel, Y.; MetzBoutigue, M. H.; Marban, C., D-Cateslytin, a new antimicrobial peptide with therapeutic potential. Sci. Rep. 2017, 7 (1), 15199.

25. Aslam, R.; Marban, C.; Corazzol, C.; Jehl, F.; Delalande, F.; Van Dorsselaer, A.; Prevost, G.; Haikel, Y.; Taddei, C.; Schneider, F.; Metz-Boutigue, M. H., Cateslytin, a chromogranin A derived peptide is active against Staphylococcus aureus and resistant to degradation by its proteases. PLoS One 2013, 8 (7), e68993.

26. Francius, G.; Polyakov, P.; Merlin, J.; Abe, Y.; Ghigo, J. M.; Merlin, C.; Beloin, C.; Duval, J. F., Bacterial surface appendages strongly impact nanomechanical and electrokinetic properties of Escherichia coli cells subjected to osmotic stress. PLoS One 2011, 6 (5), e20066.

27. Antao, E. M.; Wieler, L. H.; Ewers, C., Adhesive threads of extraintestinal pathogenic Escherichia coli. Gut Pathog. 2009, 1 (1), 22. 
28. Krogfelt, K. A., Bacterial adhesion: genetics, biogenesis, and role in pathogenesis of fimbrial adhesins of Escherichia coli. Rev. Infect. Dis. 1991, 13 (4), 721-35.

29. Connell, I.; Agace, W.; Klemm, P.; Schembri, M.; Marild, S.; Svanborg, C., Type 1 fimbrial expression enhances Escherichia coli virulence for the urinary tract. Proc. Natl. Acad. Sci. U. S. A. 1996, 93 (18), 9827-32.

30. Freudenthal, O.; Quiles, F.; Francius, G., Discrepancies between Cyclic and Linear Antimicrobial Peptide Actions on the Spectrochemical and Nanomechanical Fingerprints of a Young Biofilm. ACS Omega 2017, 2 (9), 5861-5872.

31. Quiles, F.; Saadi, S.; Francius, G.; Bacharouche, J.; Humbert, F., In situ and real time investigation of the evolution of a Pseudomonas fluorescens nascent biofilm in the presence of an antimicrobial peptide. Biochim. Biophys. Acta, Biomembr. 2016, 1858 (1), 75-84.

32. Francis, L. W.; Gonzalez, D.; Ryder, T.; Baer, K.; Rees, M.; White, J. O.; Conlan, R. S.; Wright, C. J., Optimized sample preparation for high-resolution AFM characterization of fixed human cells. J. Microsc. 2010, 240 (2), 111-21.

33. Kurtzman, C. P.; Baker, F. L.; Smiley, M. J., Specimen holder to critical-point dry microorganisms for scanning electron microscopy. Appl. Microbiol. 1974, 28 (4), 708-12.

34. Dillow, A. K.; Dehghani, F.; Hrkach, J. S.; Foster, N. R.; Langer, R., Bacterial inactivation by using near- and supercritical carbon dioxide. Proc. Natl. Acad. Sci. U. S. A. 1999, 96 (18), 10344-8.

35. Lazrag, M.; Lemaitre, C.; Castel, C.; Hannachi, A.; Barth, D., Aerogel production by supercritical drying of organogels: Experimental study and modelling investigation of drying kinetics. J. Supercrit. Fluids 2018, 140, 394-405.

36. Sneddon, I. N., The relation between load and penetration in the axisymmetric Boussinesq problem for a punch of arbitrary profile. Int. J. Eng. Sci. 1965, 3 (1), 47-57.

37. Gavara, N.; Chadwick, R. S., Determination of the elastic moduli of thin samples and adherent cells using conical atomic force microscope tips. Nat. Nanotechnol. 2012, 7 (11), 733-6.

38. Polyakov, P.; Soussen, C.; Duan, J. B.; Duval, J. F. L.; Brie, D.; Francius, G., Automated Force Volume Image Processing for Biological Samples. PLoS One 2011, 6 (4), e18887.

39. Peric, O.; Hannebelle, M.; Adams, J. D.; Fantner, G. E., Microfluidic bacterial traps for simultaneous fluorescence and atomic force microscopy. Nano Research 2017, 10 (11), 3896-3908.

40. Odermatt, P. D.; Shivanandan, A.; Deschout, H.; Jankele, R.; Nievergelt, A. P.; Feletti, L.; Davidson, M. W.; Radenovic, A.; Fantner, G. E., High-Resolution Correlative Microscopy: Bridging the Gap between Single Molecule Localization Microscopy and Atomic Force Microscopy. Nano Lett. 2015, 15 (8), 4896-4904. 
41. Zhu, Y.; Mohapatra, S.; Weisshaar, J. C., Rigidification of the Escherichia coli cytoplasm by the human antimicrobial peptide LL-37 revealed by superresolution fluorescence microscopy. Proc. Natl. Acad. Sci. U. S. A. 2019, 116 (3), 1017-1026.

42. Pogoda, K.; Piktel, E.; Deptula, P.; Savage, P. B.; Lekka, M.; Bucki, R., Stiffening of bacteria cells as a first manifestation of bactericidal attack. Micron 2017, 101, 95-102.

43. da Silva, A., Jr.; Teschke, O., Effects of the antimicrobial peptide PGLa on live Escherichia coli. Biochim. Biophys. Acta, Biomembr. 2003, 1643 (1-3), 95-103.

44. Pott, T.; Gerbeaud, C.; Barbier, N.; Meleard, P., Melittin modifies bending elasticity in an unexpected way. Chem. Phys. Lipids 2015, 185, 99-108.

45. Quiles, F.; Humbert, F.; Delille, A., Analysis of changes in attenuated total reflection FTIR fingerprints of Pseudomonas fluorescens from planktonic state to nascent biofilm state. Spectrochim. Acta, Part A 2010, 75 (2), 610-6.

46. Salomon, R. A.; Farias, R. N., Microcin 25, a novel antimicrobial peptide produced by Escherichia coli. J. Bacteriol. 1992, 174 (22), 7428-35.

47. Subbalakshmi, C.; Sitaram, N., Mechanism of antimicrobial action of indolicidin. FEMS Microbiol. Lett. 1998, 160 (1), 91-6.

48. Yonezawa, A.; Kuwahara, J.; Fujii, N.; Sugiura, Y., Binding of tachyplesin I to DNA revealed by footprinting analysis: significant contribution of secondary structure to DNA binding and implication for biological action. Biochemistry 1992, 31 (11), 2998-3004.

49. Park, C. B.; Kim, H. S.; Kim, S. C., Mechanism of action of the antimicrobial peptide buforin II: buforin II kills microorganisms by penetrating the cell membrane and inhibiting cellular functions. Biochem. Biophys. Res. Commun. 1998, 244 (1), 253-7.

50. Sim, S.; Wang, P.; Beyer, B. N.; Cutrona, K. J.; Radhakrishnan, M. L.; Elmore, D. E., Investigating the nucleic acid interactions of histone-derived antimicrobial peptides. FEBS Lett. 2017, 591 (5), 706-717.

51. Band, V. I.; Weiss, D. S., Mechanisms of Antimicrobial Peptide Resistance in GramNegative Bacteria. Antibiotics (Basel) 2015, 4 (1), 18-41.

52. Gunn, J. S., Bacterial modification of LPS and resistance to antimicrobial peptides. $J$. Endotoxin Res. 2001, 7 (1), 57-62. 


\section{Graphical Abstract}

678
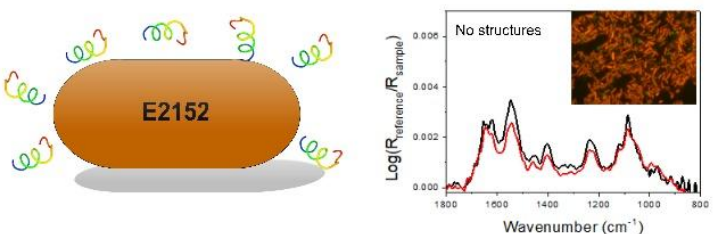

High D-Ctl activity and accumulation at bacterial cell wall
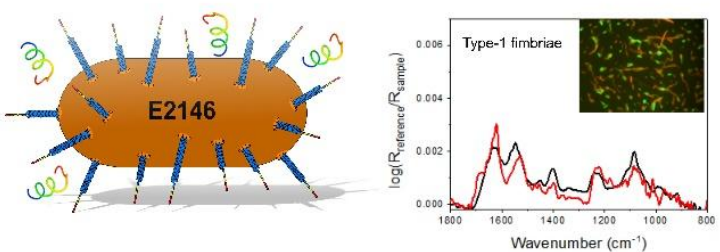

679

Low D-Ctl activity and accumulation at bacterial cell wall

680 
682

683

684

685

686

687

688

689

690

691

692

693

694

695

696

697

698

699

700

701

702

703

704

705

FIGURE AND TABLE CAPTIONS.

\section{TABLES}

Table 1. Average length $(\mu \mathrm{m})$ of bacteria in presence or not to antimicrobial peptide D-Ctl (red: average length for red bacteria in the images; green: average length for green bacteria in the images).

Figure 1: Growth curves of E. coli MDR measured at $23^{\circ} \mathrm{C}$ by the recording of the optical density at $600 \mathrm{~nm}\left(\mathrm{DO}_{600}\right)$ for different concentrations of D-Ctl. (a), (b), (c): E2152; (d), (e), (f): E2146; (a), (d) initial $\mathrm{DO}_{600}=0.001$; (b), (e): initial $\mathrm{DO}_{600}=0.01$; (c), (f) initial $\mathrm{DO}_{600}=$ 0.5 .

Figure 2. Representative epifluorescence images of E. coli E2152 submitted or not to the presence of D-Ctl at different concentrations and several times of exposure $\left(\right.$ BacLight $^{\mathrm{TM}}$ staining). (a), (e), (i): control experiment (0 x MIC); (b), (f), (j): D-Ctl at MIC (8 $\mu \mathrm{g} / \mathrm{mL})$; (c), (g), (k): D-Ctl at $5 \times \operatorname{MIC}(40 \mu \mathrm{g} / \mathrm{mL}) ;(\mathrm{d}),(\mathrm{h}),(\mathrm{l})$ : D-Ctl at $10 \times \mathrm{MIC}(80 \mu \mathrm{g} / \mathrm{mL})(\mathrm{a}),(\mathrm{b}),(\mathrm{c})$, (d): after 1 hour; (e), (f), (g), (h): after 4 hours; (i), (j), (k), (l): after 14 hours. Bars: $20 \mu \mathrm{m}$ (white), $1 \mu \mathrm{m}$ (yellow).

Figure 3. Representative epifluorescence images of E. coli E2146 submitted or not to the presence of D-Ctl at different concentrations and several times of exposure (BacLightTM staining). (a), (e), (i): control experiment (0 x MIC); (b), (f), (j): D-Ctl at MIC (8 $\mu \mathrm{g} / \mathrm{mL})$; (c), (g), (k): D-Ctl at $5 \times \mathrm{MIC}(40 \mu \mathrm{g} / \mathrm{mL}) ;(\mathrm{d}),(\mathrm{h}),(\mathrm{l}):$ D-Ctl at $10 \times \mathrm{MIC}(80 \mu \mathrm{g} / \mathrm{mL})(\mathrm{a}),(\mathrm{b}),(\mathrm{c})$, (d): after 1 hour; (e), (f), (g), (h): after 4 hours; (i), (j), (k), (l): after 14 hours. Bars: $20 \mu \mathrm{m}$ (white), $1 \mu \mathrm{m}$ (yellow). 
707 Figure 4. AFM imaging in air after $\mathrm{CO}_{2}$ critical point drying of samples of E. coli E2152

708

709

710

711

712

713

714

715

716

717

718

719

720

721

722

723

724

725

726

727

728

729

730

submitted or not to the presence of D-Ctl at different concentrations and several times of exposure. (a), (e), (i): control experiment (0×MIC); (b), (f), (j): D-Ctl at MIC $(8 \mu \mathrm{g} / \mathrm{mL})$; (c), (g), (k): D-Ctl at $5 \times$ MIC $(40 \mu \mathrm{g} / \mathrm{mL}) ;(\mathrm{d}),(\mathrm{h}),(\mathrm{l})$ : D-Ctl at $10 \times \mathrm{MIC}(80 \mu \mathrm{g} / \mathrm{mL})(\mathrm{a}),(\mathrm{b}),(\mathrm{c})$, (d): after 1 hour; (e), (f), (g), (h): after 4 hours; (i), (j), (k), (l): after 14 hours. Bar: $1 \mu \mathrm{m}$.

Figure 5. AFM imaging in air after $\mathrm{CO}_{2}$ critical point drying of samples of E. coli $\mathrm{E} 2146$ submitted or not to the presence of D-Ctl at different concentrations and several times of exposure. (a), (e), (i): control experiment (0×MIC); (b), (f), (j): D-Ctl at MIC (8 $\mu \mathrm{g} / \mathrm{mL})$; (c), (g), (k): D-Ctl at $5 \times$ MIC (40 $\mu \mathrm{g} / \mathrm{mL}) ;(\mathrm{d}),(\mathrm{h}),(\mathrm{l})$ : D-Ctl at $10 \times \mathrm{MIC}(80 \mu \mathrm{g} / \mathrm{mL})(\mathrm{a}),(\mathrm{b}),(\mathrm{c})$, (d): after 1 hour; (e), (f), (g), (h): after 4 hours; (i), (j), (k), (l): after 14 hours. Bar: $1 \mu \mathrm{m}$.

Figure 6. Morphology evolution of E. coli MDR exposed or not to D-Ctl at several concentrations; (a): Evolution of E2152 bacterial diameter in absence and in presence of DCtl after 1, 4 and 14 hours; (b): Evolution of E2146 bacterial diameter in absence and in presence of D-Ctl after 1, 4 and 14 hours.

Figure 7. In-situ monitoring of bacterial stiffness of E. coli MDR exposed or not to D-Ctl at 5 × MIC; (a): E2152 in absence and in presence of D-Ctl (black and grey squares, respectively); (b): E2146 in absence and in presence of D-Ctl (black and grey circles, respectively; (c): Evolution of stiffness ratio upon D-Ctl treatment at $5 \times$ MIC $(40 \mu \mathrm{g} / \mathrm{mL})$ for E2152 and E2146 (black rectangles and white circles, respectively); (d): In-situ monitoring of E2146 bacterial stiffness evolution after 2 injections of D-Ctl over 3 hours (D-Ctl concentration was initially set at $8 \mu \mathrm{g} / \mathrm{mL}$ and increased to $40 \mu \mathrm{g} / \mathrm{mL}$ after the second injection).. 
732 Figure 8: ATR-FTIR spectra of planktonic E. coli E2152 submitted or not to the presence of 733 D-Ctl at different concentrations after 1 hour (black spectra), after 4 hours (red spectra) and 734 after 14 hours (blue spectra). (a): control experiment $(0 \times \mathrm{MIC})$; (b): D-Ctl at MIC $(8 \mu \mathrm{g} / \mathrm{mL})$; 735 (c): D-Ctl at $5 \times$ MIC $(40 \mu \mathrm{g} / \mathrm{mL})$; (d): D-Ctl at $10 \times$ MIC $(80 \mu \mathrm{g} / \mathrm{mL})$. Key: P, proteins; NA: 736 nucleic acids; PL: phospholipids, PS: polysaccharides.

737

738 Figure 9: ATR-FTIR spectra of planktonic E. coli E2146 submitted or not to the presence of 739 D-Ctl at different concentrations after 1 hour (black spectra), after 4 hours (red spectra) and 740 after 14 hours (blue spectra). (a): control experiment $(0 \times \mathrm{MIC})$; (b): D-Ctl at MIC $(8 \mu \mathrm{g} / \mathrm{mL})$; 741 (c): D-Ctl at $5 \times$ MIC $(40 \mu \mathrm{g} / \mathrm{mL})$; (d): D-Ctl at $10 \times$ MIC $(80 \mu \mathrm{g} / \mathrm{mL})$. Key: P, proteins; NA: 742 nucleic acids; PL: phospholipids, PS: polysaccharides.

Figure 10: Tentative mechanism of action of D-Ctl at the different concentrations on E2152 (top) and E2146 (bottom). 